\title{
Information system for corporate performance assessment and reporting
}

\author{
Ondřej Popelka, Michal Hodinka, Jiří Hřebíček, Oldřich Trenz \\ Department of Informatics, Faculty of Business and Economics \\ Mendel University \\ Zemědělská 1, 61300 Brno, Czech Republic \\ ondrej.popelka@mendelu.cz,michal.hodinka@mendelu.cz,hrebicek@mendelu.cz,oldrich.trenz@mendelu.cz
}

Received: March 22, 2019. Revised: May 13, 2021. Accepted: October 20, 2021. Published: November 16, 2021.

\begin{abstract}
There are discussed current trends of corporate performance assessment (measurement of economic/financial, environmental, social and governance key performance indicators) and corporate reporting in this paper. In corporate performance assessment we focus particularly on food and agricultural sector. The core of the paper is the proposal of the prototype of information system for small and medium enterprises, which would enable various enterprises to introduce sustainable reporting. We propose a relational data model with several abstract entities to represent various differences in various reporting frameworks. Our goal is to design a generic information system which may be used by small and medium enterprises to start with their corporate performance assessment and reporting. The overall structure of the information system is described in the paper, along with the core data model and possible extensions into XBRL based reporting and business intelligence. Corporate performance, Information system, XBRL, SAFA,
\end{abstract}

Keywords - Corporate reporting, Performance assessment, Key performance indicators

\section{INTRODUCTION}

The research teams of Faculty of Business and Management (FBM) of Brno University of Technology (BUT) and Faculty of Business and Economics (FBE) of Mendel University in Brno (MENDELU) are taking part in the research project No P403/11/2085 "Construction of Methods for Multifactorial Assessment of Company Complex Performance in Selected Sectors" since January 2011. The project is being solved through years 2011-2014 and funded by the Czech Science Foundation. The main goals of the research in this project have are specified by its six partial research targets [10], [14]:

- The analysis of the state-of-the-art of economic, environmental, social and governance aspects of corporate performance through targeted research of the global information and database sources available at the FBM BUT and the FBE MENDELU with using available Information and Communication Technologies (ICTs) tools.

- A detailed analysis of the implementation of economic, environmental, social and governance reporting in chosen economic activities and its justification.

- Assessment, analysis, and the categorization of contemporary characteristics of the individual pillars of corporate performance in relation to the measure of progress or dynamics of the development of overall corporate performance.

- The identification of the importance and relative roles of Environmental, Social and Governance (ESG) factors using ESG data and Key Performance Indicators (KPIs) in the overall company performance.

- The construction of quantitative and qualitative methods of the multifactor measurement of corporate performance in the chosen economic activities with the use of ICT tools.

- An application of developed methods for multifactor measurement of corporate performance of chosen economic activities in practice with feedback for possible change correction aimed at further improvement.

\section{CORPORATE REPORTING}

Reporting on sustainability and environmental, social and governance (ESG) performance is a crucial step toward a market that rewards the creation of long-term wealth in a just and sustainable society. Sustainability key performance indicators can play a crucial role in supporting markets that create such long term wealth [9]. They can form the backbone of sustainability disclosure that tracks, and allows for improvement on, those issues most tied to a corporation's environmental and social impact and most material to a company's financial performance [13].

Nowadays we can see significant change how reporting systems are evolving. They are moving form usage of few analysts to ubiquitous use across many organizational functions. We focus to develop an information system accessible to smaller and medium-sized enterprises (SME). Large corporations usually already have some kind of reporting system implemented. SMEs usually do only mandatory reporting required by laws only to fulfill regulatory demands. Our goal is to facilitate SME performance reporting even for these companies and make it as easy as possible. This should help enhance strategic decision making and planning of SMEs which in turn helps to improve risk management and sustainability of the business and its environment.

The Food and Agriculture Organization of the United Nations (FAO) is developing the Sustainability Assessment of 
Food and Agriculture systems (SAFA) guidelines [17] to assist the achievement of fair practices in food and agriculture production and trade on a local and regional level. The SAFA framework is the result of an iterative process, built on the cross-comparisons of codes of practice, corporate reporting, various standards, indicators and other technical protocols currently used by food and agricultural enterprises that implement sustainability assessment.

The structure and methodology of the SAFA Guidelines draw specifically upon: ISO 14040:2006, the ISEAL Code of Good Practice [11], the Reference Tools of the Global Social Compliance Programme, the Sustainability Reporting Guidelines [3] and its Food Sector Supplement of the Global Reporting Initiative. The SAFA Guidelines - currently in test version - will be revised and finalized in 2013 in order to improve their practicality and applicability.

The guiding vision of SAFA is that food and agriculture systems worldwide are characterized by environmental integrity, economic resilience, social well-being and good governance. In recent years, there has been some progress in the realization and acknowledgement of sustainable development, which is summarized in [5], [7] [8] and [9]. Many stakeholders in the agriculture sector have contributed to this progress by improving agricultural productivity, protecting natural resources and human resources by implementing frameworks and standards for assessing and improving sustainability across the agricultural sector and along the value chain [17].

The SAFA guidelines consist of three core sections SAFA framework, SAFA implementation and Sustainability dimensions [17]. In the following chapters, we describe a special information system, whose role may be divided into several main steps:

- collecting data;

- reporting;

- $\quad$ standardized format for the purpose of stakeholders and required regulatory demands;

- standardized interchange format XBRL;

- customized reporting;

- evaluating company performance by computing standardized key performance indicators.

These steps correspond to last four steps of Section 2 of SAFA framework implementation (select tool, collect data, aggregate results, reporting). Covering the first two steps (setting goals and checking compliance and relevance) seems currently impractical, due to highly specific nature of the problem for each reporting SME / corporation. Therefore, these steps are not considered a part of the proposed information system.

One of our goals is development of special information system or information system module for SME performance reporting. Such organizations would be able to use such system to generate standardized reports and assess their corporate performance.

\section{OVERVIEW OF EXISTING PERFORMANCE INDICATORS}

While we concentrate mainly on agricultural organizations, the SAFA methodology is highly important to us. To allow greater generality of the information system for SMEs we have also considered and evaluated other performance methodologies and their indicators.

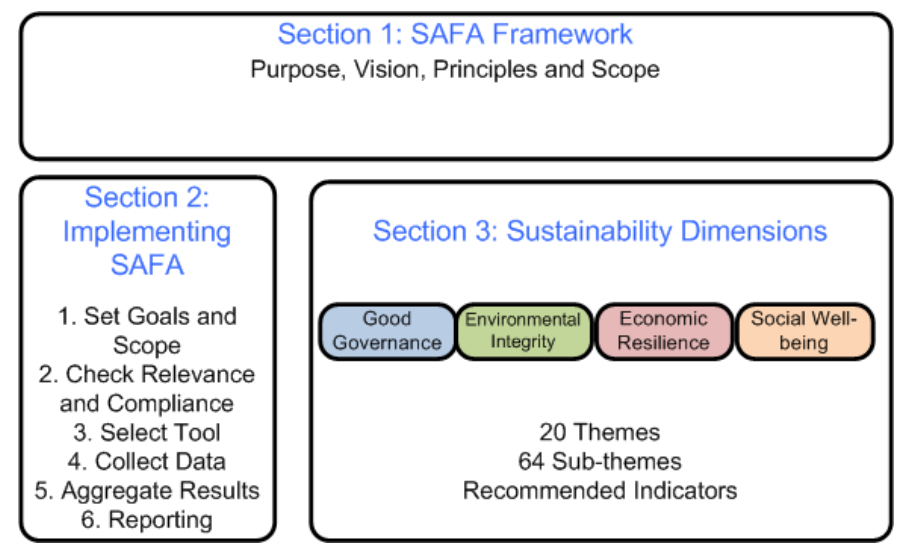

Fig. 1. SAFA Guidelines structure [17]

In March 2011, the GRI released the G3.1 Guidelines [1], an update and completion of the G3 Guidelines from 2006 [4], which consist of two parts. The part 1 features the guidance on how to report. The part 2 features the guidance on what should be reported, in the form of Disclosures on Management Approach (DMA) and Performance Indicators (PI), which are organized into categories: Economic, Environmental and Social. The GRI guidelines are probably the most comprehensive guide covering both what information should be reported and how this information should be provided. The GRI guidance does not directly include corporate governance group of performance indicators, but new release G4 will bring this. It will come in the half year 2013.

There are a number of alternative reporting methodologies that focus more on what should be reported, rather than how it should be reported. An example is AEI EU (AgriEnvironmental Indicators of European union). Defined AEIs EU [1] are not yet generally usable in practical generic reporting for SMEs in agricultural sector [9]. Some of the indicators cannot be computed because of missing data, sometimes the data required are not homogenous enough [5], [7]. Because these indicators are designed mainly for the purpose of CAP EU (Common Agricultural Policy of EU) they should be considered usable only for special cases of farms. As such, they are divided into completely different domains and subdomains, because the Driving force - State - Response framework is used (responses, driving forces, pressures and benefits and state/impact). In addition, they focus solely on environment monitoring and are completely missing both economic and corporate governance domains [8]. The same problems bring application of indicators tracked by European Environment Agency [12]. Again, these are concentrating solely on environmental domain and are unsuitable for complex performance reporting. The main reason for the 
evaluation of these AEIs was that they are highly desirable to develop tools, which will be capable of producing required values of these indicators if necessary.

Another set of standardized performance indicators comes from collaboration of OECD, Eurostat, and Food and Agriculture Organization (FAO) [16]. Although these indicators are not based on the Driving force - State Response framework, they are still primarily agroenvironmental indicators and are therefore insufficient for complex sustainability reporting.

Within the solution of the project GACR 403, we have proposed a minimal set of generic key performance indicators [10], [13] applicable to a wide range of enterprises. This forms one set of indicators used considered for implementing and validating the information system prototype. Second set of testing indicators are indicators described in Methodology for assessing the sustainability of crop production systems for the conditions of the Czech Republic [15], [19]. The rationale behind these choices is that we want to test both simpler (and generic) reporting systems such as the one proposed by [13] and complex reporting systems of indicators such as SAFA or [15], [19].

Our goal is to provide architectural proposal generic enough to contain all of the above-described methodologies. To implement such system successfully several abstractions are required. These need to be carefully constructed to ensure that they are hidden before the end-use and do not add any more complexity to the corporate reporting itself.

\section{SYSTEM REQUIREMENTS AND GOALS}

In our vision, we foresee two main goals of the reporting information system. A company may use such system to create various reports and share data with both its' stakeholders and in future with state institutions for regulatory demands and mandatory reporting. The second goal is company performance assessment performed by evaluating key performance indicators by the means of one of the proposed methodologies. This way, the company can share with public its performance or check a performance development progress. Evaluating company performance can be done thru various reports as stated above or thru custom dashboards. This is further summarized on the excerpt of the use case diagram (Figure 2).

We define the following three main generic actors:

- Reporter - a person responsible for ensuring company mandatory reporting (especially financial, social and environmental) or reporting for stakeholders, this would be typically a member of the accounting team or a contractor. This is the typical actor, which would enter data into the information system.

- Evaluator - a person responsible for evaluating company performance, this can be a wide range of persons starting with managers, auditors and various internal interested parties. Evaluator may also enter data into the information system, but it is not as his primary task, typically this would be additional data required for report generation but not required as the part of mandatory reporting (e.g. company strategy, goals a targets, vision etc.)

- Administrator - the administrator of the information system responsible for defining report templates and business rules used to generate reports.

Reporting system should include flexible layout design, rich visualization, business requirements and data logic definition. In addition, there is the need for translation or publishing requirements, a central deployment and the customization of interactive reports. These primary functions represent good reporting system with strong delivery capabilities of relevant reports. From the definition of the generic roles, we can proceed to basic functional requirements. Basic high-level requirements are:

- store source company data;

- compute of performance indicators according to selected methodology;

- generate of reports in selected format in for offline storage, printing and archiving;

- import of source company data from company information system;

- provide selected information in the form of reports online accessible to general public or only to selected persons;

- provide selected information in standardized XBRL format for interchange with other systems;

- provide possibility to evaluate company performance anonymously;

- provide possibility to define report data and business logic;

- dynamically generate XBRL taxonomies for a given report;

- provide possibility to customize standardized reports and to generate fully custom reports;

- provide possibility to compare reports.

Non-functional requirements:

- system must be easy to use and accessible to general public (not just few data analysts);

- as many indicator values as possible should be computed or imported from external sources;

- system must be possible to provide the software as a service (SAAS) for cloud computing;

- report layouts must be flexible;

- report visualizations should be rich and interactive.

For all use cases of the generic actors - reporter and evaluator - we consider two scenarios. The system may be used either on regular basis (registered company scenario) to generate scheduled company reports (annual, quarterly etc.) 
performance and to check trailing company performance and its development. The second scenario (anonymous company) represents the case when a company wants to generate a onetime irregular report. This can occur for example when company is applying report for a subsidy or grant or when company is evaluating changes in company operation (e.g. restructuring) where a report would be generated for the period before the change and for the period after the change. The second scenario can also be seen as an entry point into the reporting system for companies that do not use it regularly.

\section{SYSTEM STRUCTURE}

The information system consists of several modules that can be separated into two main groups - data collection and data retrieval. The data collection module may occur for the two scenarios described above. Hence, there are two its main modules RegisteredCompanyModule and SurveyModule. The former allows entering data on regular basis by registered users of for registered companies in information system. The latter allows entering data anonymously, for several years at once. The third data retrieval module is ImportModule that represents interface between the information system and external sources. This can be used in conjunction with both RegisteredCompanyModule and SurveyModule. The import module must be able to import data in XBRL format, also it should be able to import data from other sources, but this is highly dependent on used performance assessment methodology. In these modules there are also included the operations of document validation and application of defined business rules.

Data retrieval modules include also ReviewModule which is a basic document viewer used for reviewing entered data regardless of the used reporting framework. The second important module of data retrieval is ReportModule that generates the reports according to the selected methodology for the end-user. Both modules may use several different internal modules, which provide the system with indicator mapping, and additional processing of optional business rules regarding the report output (e.g. how often should the report be generated or uniform visual style etc.). The internal modules include XBRLReportModule that provides the data in form of a XBRL document; this module may also be used directly for exporting reports in interchangeable format.

The above-described architecture describes the portion of the information system build as a transactional system utilizing relational database, which forms the main data storage system. We have proposed further extension of the information system with XML and XBRL data store to provide greater flexibility.

\section{INDICATOR ABSTRACTION}

To encompass the above defined rules and different methodologies described in the previous chapter, we propose the following abstraction of performance indicators (applicable universally to both key performance indicators and additional performance indicators [3]). For the prototype application, we have used a relational database as a storage system. Hence, the following description uses relational database technology. See following chapter for the discussion of other storage options. The basic indicator abstraction entities are:
- indicator group;

- indicator;

- indicator item;

- indicator item aspect.

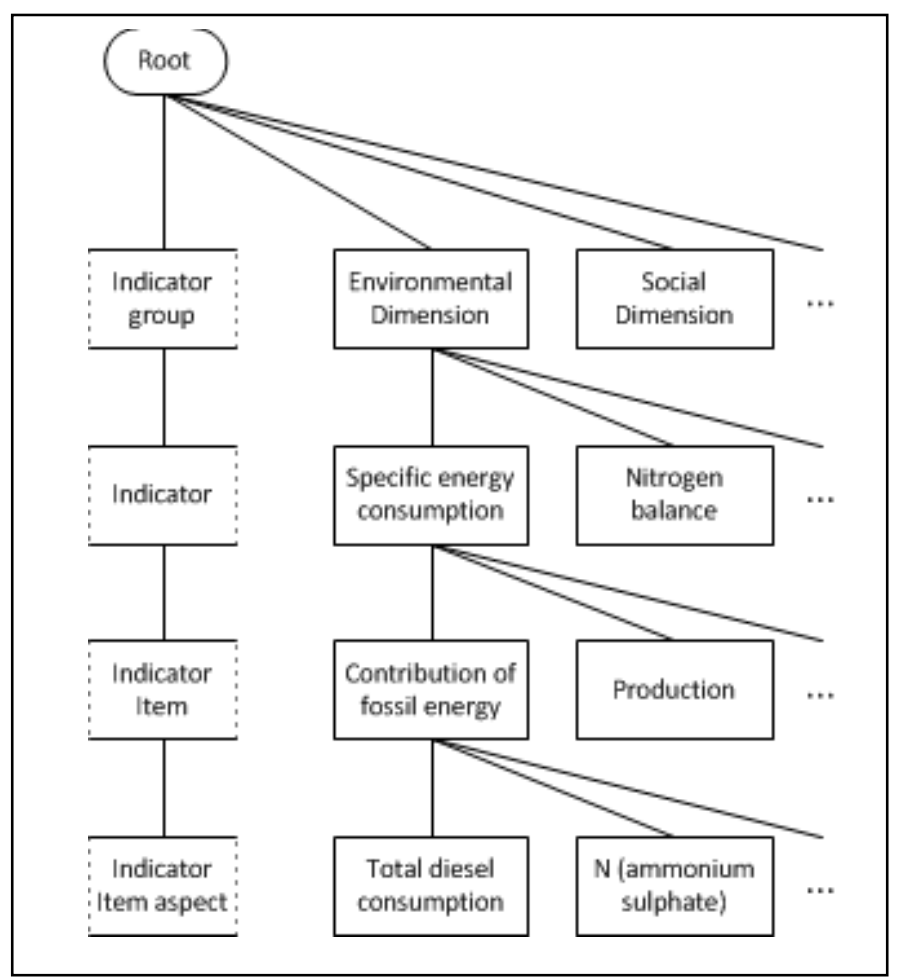

Fig. 1 Structuring of indicators with sample concrete indicators from methodology [15]

These entities are organized into a hierarchical structure shown on Figure 1. Each indicator sub-entity is shown along with examples of real values according to methodology [15].

The end user will always fill in leaves of this tree structure - i.e. if an indicator value is not computed and contains only one value it may contain only a single indicator item, which will contain no aspects. The concrete example may be an indicator average number of employees, which is the value directly known to the company and a value directly used in a report. It is important to note that an indicator group must always have at least one indicator and all indicators must have at least one indicator item while an indicator item may have zero or more indicator item aspects. This is important to maintain flexibility of the system. In case the indicator item contains several aspects, it is expected that, all of them are required for indicator item value computation unless specified otherwise in indicator item formula.

The entities described above define the core of the data model of the information system. The following schema (Fig. 2) shows further details with associated entities. Here we defined a report type, which represents an instance of a given methodology e.g. SAFA version 1.2 [17]. We have also introduced a report instance that represents a concrete filled report for a specific company for a specified time period. The 
indicator value, which is an actual value entered by end user, may be bound to either indicator item or indicator item aspect but not both. Note that the indicator value is not actually related to a report instance. This is internal so that a single indicator value may be reused in several report instances. For example the value of indicator average number of employees may be used both in SAFA 1.2 report for year 2011 and also for the mandatory financial report for the same period. As long as the period is same, the value should be reused. This is crucial to maintain the consistency of data across different reports and it is a highly important feature to make reporting as easy and quick as possible.

There is also the indicator report group entity, which defines grouping of indicators in the defined report types. The linkage is provided by the indicator report types association table which assigns indicators to specific groups in specified report types. Note that it is possible that an indicator is used in more than one report definition, which is desired behaviour. It is also possible that an indicator is used in more than one group, which is also desired behaviour. For example, the indicator average salary may be part of the economic indicators group in the report or it may be part of social responsibility group or even both.

The actual computation of reported indicator value is provided by the formula code defined in indicator, indicator item and indicator item aspect entities. The formula API (Application Programming Interface) is discussed further in the text. The computed value is not stored in the schema shown in Figure 4, because it is recoverable from base values. However, for performance and / or version tracking reasons the computed values may be stored in caching schema.

The entities: indicator value, indicator item, and indicator item aspect all link to data type. Value data types' model is shown on Fig. 3. Here we define another entity named Core data type which represents a XBRL native type (e.g. monetary, numeric, fractional etc.). This is because the XBRL data types are too coarse for all kinds of reports. The definition of a constraint also uses the formula API in following chapters.

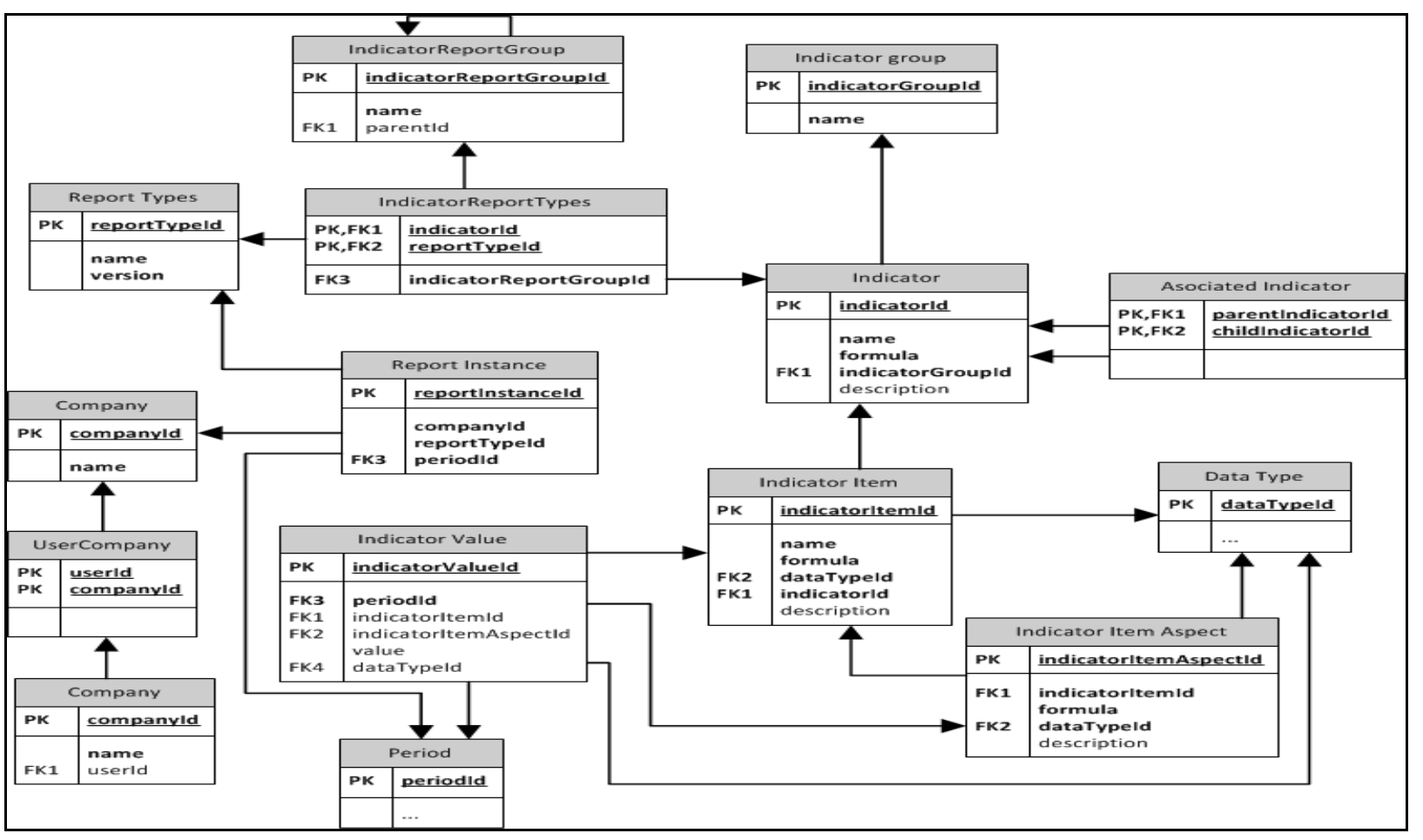

Fig. 2. Core data model of the reporting system

Closely linked to an indicator value computation is also the Associated Indicator table. This is used to track dependencies between indicators in case when one indicator is used for computation of another indicator.

The concrete example can be seen in methodology [14] where economic performance indicator EE14 - Expenses on $R \& D$ is computed as the value of Total costs of $R \& D$ of company divided by value of economic indicator EEO1 Value added of company and expressed in per cents. The EE01 - Value added is the economic performance indicator of [13] defined as the value added of company per employee.
The further economic performance indicator EE02 - Value added to / vis á vis of the personal costs was introduced [13]. Both EE01 and EE02 indicators are computed as value added of company divided by average number of its employees in the year for the former and by payroll costs for the latter.

To fully represent the above-mentioned indicators, we need to define the following indicators in the application:

- source indicator: Total costs of R\&D;

- source indicator: average number of employees; 
- $\quad$ source indicator: payroll costs;

- source indicator: value added of company;

- output indicator: EE14 - Expenses on R\&D;

- output indicator: EE01 - added value per employee;

- output indicator: EE02 - added value to personnel costs.

Note that the separation of indicators into source and output indicators is purely explanatory, there is no such division made in the data model as any indicator may be used in any report. Because of this, it is important to maintain associations between indicators (or potential indicators) so that when the user decides to fill a given type of report, all of the required values are requested - that is all indicators and their associated, see Figure 3.

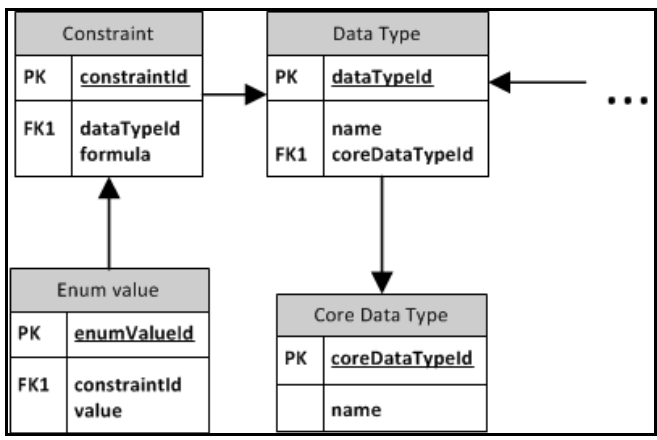

Fig. 3. Data type data model

\section{INDICATOR COMPUTATION}

The actual values of indicator values for a report are computed from the indicator items and indicator item aspects. The computation itself is provided by formula defined in each of these entities. The formula is a piece of executable code used to compute the value from source data. Currently in our prototype of information system, the formula is defined as PHP code. This is the native language of the information system. In future, it might be better to switch to another interpreted language such as JavaScript, which would provide more flexibility and portability. Regardless of the formula language used, the following data API is proposed.

Each indicator may have associated indicator values, these are values used in more indicators at once. The concrete example would be indicator added value, which is used as both a report indicator and also as common divisor for several other indicators in the methodology [14].

The API for the formula code has one base available entity: indicator. The properties defined in each entity correspond to those defined in the data model. The computation must return a single value of arbitrary data type. We expect that a single report indicator must always have a single value. This may pose a limitation on the report generator, because the end user might want to obtain a list of values in a report. Currently it is only possible to convert data type among indicator, indicator item and indicator item aspect it is also possible to generate strings of characters from raw input values. In future development we will see whether such solution is sufficient or whether multivalued data types will be required.

When working with the formulas, the question of versioning comes into attention. All methodologies are being constantly updated and the computations may change so it is required to keep track of historic data - definitions of indicators. We have proposed a standard recording of history where after each change in the formula a new physical indicator is created, while maintaining the link to the original indicator. That is, when an indicator is modified, the new indicator is created which supersedes the original indicator. The above principle applies to all core entities of the data model (i.e. indicators, indicator items, indicator item aspects).

\section{CONCLUSIONS}

We have implemented a prototype of the described special reporting information system. There have been two primary goals of the prototype implementation: verify that the proposed indicator abstraction can be implemented successfully and to verify usability of the information system for end-users. Though our main goal is implementation of SAFA Guidelines methodology [17], we have currently implemented the Methodology for assessing the sustainability of crop production systems for the conditions of the Czech Republic [15] because SAFA Guidelines version 1.2 are currently only in a test version. As far as usability is concerned, we are currently testing two approaches to user interface - survey interface and guide interface. In the former interface, the user can enter all required and optional values on a single page form with minimum structuring. In the latter case, the user is lead thru various steps filling different parts of the report gradually.

Following the SAFA vision [17], we use four dimensions of sustainability: good governance, environmental integrity, economic resilience and social well-being. The proposed system is able to deal with other performance assessment frameworks and guidelines. Our future work will concentrate on improving XBRL reporting by adding dynamic XBRL taxonomies and XBRL database layer. Also we will concentrate on improving the end-user experience of the report outputs so that performance evaluation becomes available to wide range of users. This would be accomplished by utilizing business intelligence tools to add a set of dashboards and overviews to the report [5].

\section{ACKNOWLEDGMENT}

This paper is supported by the Czech Science Foundation. Name of the Project: Construction of Methods for Multifactor Assessment of Company Complex Performance in Selected Sectors. Reg. No P403/11/2085.

\section{REFERENCES}

[1] Analytical framework. European Commision. Eurostat Home [online]. 2010, Avaliable from : http://epp.eurostat.ec.europa.eu/portal/page/portal/agri_environmental _indicators/introduction/analytical_framework

[2] Z. Chvátalová, A. Kocmanová and M. Dočekalová, "Corporate Sustainability Reporting and Measuring Corporate Performance," in 
Proceedings of 9th IFIP WG 5.11 International Symposium. ISESS 2011. Environmental Software Systems. Frameworks of eEnvironment. J. Hřebíček, G. Schimak, R. Denzer, Eds. Heidelberg: Springer, 2011, pp. 398-406.

[3] G3.1 Guidelines on Globalreporting. 2011. [Online]. Available from: https://www.globalreporting.org/reporting/latest-guidelines/g3-1guidelines/Pages/defaultaspx

[4] G3 Guidelines website on Globalreporting. 2006. [Online]. Available from: https://www.globalreporting.org/reporting/latestguidelines/g3-guidelines/Pages/default.aspx

[5] M. Hodinka and M. Štencl, "Reporting Tools for Business Rules," In IT for Practice 2011. Ostrava: VŠB Technická univerzita Ostrava, 2011, pp. 29-36

[6] M. Hodinka, M. Štencl, J. Hřebíček and O. Trenz, "Business intelligence in Environmental reporting powered by XBRL," Acta univ. Agric. Et silvic. Mendel. Brun., 2013. in press

[7] J. Hřebíček, O. Trenz and E. Vernerová "Optimal set of agrienvironmental indicators for the agricultural sector of Czech Republic,” Acta univ. agric. et silvic. Mendel. Brun., 2013. in press.

[8] J. Hřebíček, M. Popelka, M. Štencl and O. Trenz, "Corporate performance indicators for agriculture and food processing sector," Acta univ. Agric. Et silvic. Mendel. Brun., Vol. 60, pp. 99-108, February 2012.

[9] J. Hřebíček, S. Dušková, J. Křen, M. Hodinka, O. Trenz and P. Marada, "Sustainability indicators: development and application for the agriculture sector," in Sustainability Appraisal: Quantitative Methods and Mathematical Techniques for Environmental Performance Evaluation, M. G. Erechtchoukova, P. Khaiter and P. Golinska, Eds. Heidelberg: Springer, 2013, pp. 63-102.

[10] J. Hřebíček, M. Štencl, O. Trenz and J. Soukopová, "Current Trends in Corporate Performance Evaluation and Reporting in the Czech Republic," International Journal of Energy and Environment, WSEAS Press, Vol. 6, pp. 39-48, January 2012.

[11] ISEAL Alliance. Assessing the impacts of environmental and social standards systems. ISEAL Code of Good Practice, version 1.0. ISEAL Alliance, London Available from: http://www.isealalliance.org/resources/p041-impactscode-of-goodpractice.

[12] Indicators: European Environment Agency. European Environment Agency [online]. Copenhagen, 2013. Available from: http://www.eea.europa.eu/data-and-maps/indicators

[13] A. Kocmanová, M. Dočekalová, "Construction of the economic indicators of performance in relation to environmental, social and corporate governance (ESG) factors," Acta univ. agric. et silvic. Mendel. Brun., Vol. 60, pp. 195-205. April 2012.

[14] A. Kocmanová, M. Dočekalová, P. Němeček, and I. Šimberová, "Sustainability: Environmental, Social and Corporate Governance Performance in Czech SMEs,". in The 15th World Multi-Conference on Systemics, Cybernetics and Informatics. IFSR, Orlando, USA: WMSCI, 2011, pp. 94-99.

[15] J. Křen, Methodology for assessing the sustainability of crop production systems for the conditions of the Czech Republic. Brno: Mendel University in Brno, 2011.

[16] OECD. Environmental Indicators for Agriculture Volume 1: Concepts and framework [online]. Paris: OECD, 1999 Avaliable from: http://www.oecd.org/agriculture/sustainableagriculture/40680795.pdf

[17] Sustainability Assessment of Food and Agriculture systems - Food and Agriculture Organization of United Nations, 2012, Available from:

http://www.fao.org/fileadmin/templates/nr/sustainability_pathways/d ocs/SAFA_Guidelines_Test_Version_1.1.pdf.

[18] J. Soukopová and E. Bakoš, "Assessing the efficiency of municipal expenditures regarding environmental protection," in Environmental Economics and Investment Assessment. III. ed. Cyprus. WIT Press. 2010, pp. $107-119$.

[19] S. Valtýniová and J. Křen,"Indicators used for assessment of the ecological dimension of sustainable arable farming - review,", Acta univ. agric. et silvic. Mendel. Brun., Vol. 59, pp. 247-256, March 2011

\section{Creative Commons Attribution License 4.0 (Attribution 4.0 International, CC BY 4.0)}

This article is published under the terms of the Creative Commons Attribution License 4.0

https://creativecommons.org/licenses/by/4.0/deed.en_US 